\title{
TEMPAT SANTAI DI BLOK M
}

\author{
Ricky Setiadi ${ }^{1)}$, JM.Joko Priyono Santoso ${ }^{2)}$ \\ 1)Program Studi S1 Arsitektur, Fakultas Teknik, Universitas Tarumanagara, rickysetiadi89@gmail.com \\ 2) Program Studi S1 Arsitektur, Fakultas Teknik, Universitas Tarumanagara, jokop@ft.untar.ac.id
}

\begin{abstract}
Abstrak
Kawasan Blok $M$ yang merupakan bagian dari DKI Jakarta yang tidak pernah berhenti aktivitasnya. Hal ini dikarenakan kawasan Blok $M$ salah satu kawasan perniagaan dan perkantoran yang dominasi pekerjaannya adalah pedagang dan karyawan guna memenuhi kehidupan sehari-hari baik primer dan sekunder. Akibat dari padatnya aktivitas timbulah tingkat stress pada kawasan Blok M. Permasalahan lain yang mengakibatkan tingkat stres meningkat di kawasan Blok $\mathrm{M}$ adalah padatnya bangunan sekitar yang tidak sehat. Bangunan sekitar kurang adanya cahaya maupun udara yang masuk, menyebabkan rasa jenuh, bosan, dan tertekan akibat ruang terbuka yang minim. Oleh karena itu dibutuhkannya area bersifat relaksasi, rekreasi, dan sosialisasi yang sifatnya publik namun privasi, dapat keluar-masuk secara aman dan nyaman tanpa adanya batasan-batasan tertentu. Tujuannya untuk merelaksasi pikiran dan tenaga setiap individu yang berada di kawasan Blok M. Penelitian ini menggunakan dua metode yakni metode pengumpulan data baik secara primer dan sekunder serta metode komparatif. Dari hasil penelitian maka di usulkan sebuah third place di kawasan Blok $M$ dalam menanggapi kondisi dan isu tersebut. Diusulkan dalam bangunan adanya penerapan biopihilic design berupa ruang terbuka dan hijau serta program kegiatan berkaitan yang diharapkan dapat membantu mengurangi tingkat stres pada seseorang sebagai akibat dari aktivitas yang dilakukan setiap hari di kawasan Blok M. Program utama dalam proyek ini yaitu berupa foot bathtub, theme onsen, temper clinic, area tidur, area nonton, dan coffee shop yang terbagi beberapa ruang yang bertujuan untuk mewadahi aktivtias sosial yang dapat merangkul masyarakat tanpa adanya batasan tertentu di kawasan Blok $\mathrm{M}$.
\end{abstract}

Kata kunci: stres ; relaksasi; rekreasi

\begin{abstract}
Blok $M$ region is part of the DKI Jakarta which never stops its activities. This is because Blok $M$ is one of the business and office areas where work is dominated by traders and employees to provide primary and secondary daily life. As a result of the high levels of activity is stress level growing in the Blok $M$ region. Another problem that causes stress levels in the Blok $M$ area is that the surrounding buildings are unhealthy. A building is either lacking in light and in air, causing tedium, boredom, and depression as a result of minimum the open space. Therefore, the need an area for a relaxation, recreation, and socialization which stately privacy, can slip in and out of here safely and comfortably without certain restrictions. The goal was to relax the thought and energy of each individual in the Blok $M$ region. The study using two methods of both primary and secondary data collection and comparative methods. The research result suggests a third place in Blok $M$ in response to the conditions and issues. It is proposed in the building with the application of biopihilic design of open and green space and a related activity program that is expected to help reduce someone's stress levels a sa result of daily activities in the Blok $M$ region. A major program of this project is foot bathtub, theme onsen, temper clinic, sleeping areas, viewing areas, and the coffee shop which is divided into some space that aims to bridge the social activity that can reach people with no boundaries in the Blok $M$ region.
\end{abstract}

Keywords: stress; relaxing; recreation 


\section{PENDAHULUAN}

\section{Latar Belakang}

Kawasan Blok M yang merupakan kelurahan dari Kebayoran Baru, Jakarta Selatan adalah bagian dari DKI Jakarta, merupakan kawasan perdagangan dan perkantoran yang dominasi pekerjaannya adalah pedagang dan karyawan. Aktivitasnya tidak pernah berhenti setiap waktunya guna memenuhi kehidupan sehari-hari baik primer dan sekunder yang mengakibatkan tingkat stres meningkat. Pada tahun 2019 DKI Jakarta masuk ke dalam sepuluh besar di dunia sebagai kota yang di dalamnya termasuk kawasan Blok $\mathrm{M}$, memiliki masalah stres akibat pekerjaan. Hal ini terjadi dikarenakan aktivitas berulang-ulang yang dilakukan setiap hari.

Permasalahan lain yang mengakibatkan tingkat stres meningkat di kawasan Blok $\mathrm{M}$ adalah padatnya bangunan yang tidak sehat. Setiap bangunan sekitar kurang adanya cahaya maupun udara yang masuk mengakibatkan tingkat stres meningkat dikarenakan minimnya ruang terbuka. Dibutuhkan ruang publik yang dapat mewadahi para pedagang, karyawan, maupun masyarakat yang datang di kawasan Blok $\mathrm{M}$ untuk mengisi waktu kosong mereka dengan aman dan nyaman tanpa adanya batasan tertentu serta terbuka secara umum agar setiap individu yang datang dapat merelaksasikan dirinya di waktu tertentu untuk menghilangkan kejenuhan, kebosanan dan tertekan akibat pekerjaan yang terjadi di kawasan Blok M.

Untuk menjawab kebutuhan tersebut maka di usulkan sebuah third place di kawasan Blok M dalam menanggapi kondisi dan isu tersebut. Oleh sebab itu Diusulkan dalam bangunan adanya penerapan biopihilic design berupa ruang terbuka dan hijau serta program kegiatan berkaitan yang diharapkan dapat membantu mengurangi tingkat stres pada seseorang sebagai akibat dari aktivitas yang dilakukan setiap hari di kawasan Blok M. Program utama dalam proyek ini yaitu berupa Foot Bathtub, Theme Onsen, Temper clinic, Area Tidur, Area Nonton, dan Coffee Shop yang terbagi beberapa ruang yang bertujuan untuk mewadahi aktivtias sosial yang dapat merangkul masyarakat tanpa adanya ruang batasan di kawasan Blok $\mathrm{M}$.

\section{Rumusan Permasalahan}

a. Kawasan Blok $\mathrm{M}$ merupakan kawasan perdagangan dan perkantoran yang aktivitasnya tidak pernah berhenti setiap waktunya, mengakibatkan tingkat stres meningkat. Apakah program untuk menghilangkan tingkat stres ?

b. Padatnya bangunan sekitar yang tidak sehat serta minimnya kapasitas ruang untuk berinteraksi sosial menimbulkan tingkat stres di kawasan Blok M. Apakah sebuah bangunan third place yang terbuka, sehat, dan mudah di akses oleh semua kalangan mampu menarik serta menjawab kebutuhan ruang masyarakat pada kawasan Blok $\mathrm{M}$ ?

\section{Maksud}

Mengumpulkan dan menganalisa data kawasan Blok $\mathrm{M}$ yang merupakan kawasan perniagaan dan perkantoran yang aktivitasnya tidak pernah berhenti, memungkinkan setiap individu menjadi bosan, jenuh, dan tertekan sehingga dapat memicu tingkat stres meningkat.

\section{Tujuan}

Menciptakan third place bagi masyarakat di kawasan Blok $\mathrm{M}$ untuk menghilangkan rasa bosan, jenuh, dan tertekan yang memicu stres akibat rutinitas pekerjaan. Selain itu dapat dijadikan wadah yang sifatnya publik sebagai kegiatan berinterkasi satu sama lain didalamnya tanpa adanya batasan tertentu, mudah di akses dengan aman dan nyaman. 


\section{KAJIAN LITERATUR}

\section{Open Architecture}

Dalam buku "Making People-Friendly Towns: Improving the Public Environment in Towns and Cities" (Tibbalds, 1992:1), keberadaan ruang publik dalam sebuah kota seperti jalan raya, taman kota, alun - alun kota, jalur pedestrian, bulevar dan sebagainya, merupakan kesatuan ruang atau tempat yang utuh dimana menjadi milik bersama dan memegang unsur yang sangat penting dalam sebuah morfologi kota.

Open Architecture for the Third Place di definisikan sebagai hal yang dibutuhkan oleh masyarakat yang sifatnya mengarah kepada individualis dan teknologi, sehingga timbulnya jarak interaksi antara sesama, adanya jurang pembatas terhadap orang yang tidak dikenal, dan transparan. Dalam merancang bangunan arsitektur perlu mencari kearifan dari luar masyarakat kota karena masyarakat kota yang bersifat individual dan lebih sensitif terhadap personal spacenya. Dalam buku yang berjudul "Wastu Citra" (Dipl. Ing. Yusuf B. Mangunwijaya, 1992), arsitektur tidak hanya berfokus pada statika bangunan agar kokoh dan tahan gempa, tetapi harus adanya kebebasan serta keindahan secara psikologi interpenetrasi dalam ruang, selain itu tidak hanya menyangkut paragmatik denah, penyusunan zona bisnis, ekonomi, industri, dan sebagainya saja, akan tetapi menyentuh dimensi yang sudah disentuh oleh alam raya.

Dari pernyataan tersebut maka open architecture merupakan konsep yang terbuka terhadap segala hal yang terjadi. Pada pelaksanaanya open architecture sebagai sebuah tempat ketiga yang sifatnya rembesan antara tempat pertama yaitu tempat tinggal, dan tempat kedua yaitu tempat untuk bekerja. sebagai program bagi masyarakat kota akibat rasa bosan, jenuh, dan tertekan akibat rutinitas yang terjadi setiap hari. Sehingga terciptanya masyarakat sosial yang bersifat dinamis, produktif, dan yang paling penting terbuka bagi siapapun. Alasan itulah yang akhirnya open architecture membuat kesempatan untuk menciptakan bangunan arsitektur yang dapat dijadikan solusi pada pendekatannya baik dari desain maupun strategi perancangannya sesuai dengan kondisi masyarakat yang terjadi pada kota besar seperti DKI Jakarta.

\section{Third Place}

Dalam buku "The Great Good Place" (Ray Oldenberg, 1989), merupakan tempat untuk orang yang ingin mengobati stres, kesepian, dan keterasingan. Pengertian dari third place sendiri adalah suatu tempat yang bisa dijadikan tempat berlindung sementara dari kebosanan, tidak hanya dijadikan tempat untuk melarikan diri, tetapi dimana orang akan bersantai dan terasa terhibur, juga mendapatkan ketenangan di dalamnya. Tempat ketiga memiliki efek personal yang signifikan dalam menyenangkan dan mempertahankan individu, serta manfaat sosial dalam menciptakan hubungan yang lebih baik antara orang lain. Dia menyesali bahwa kenyataannya pentingnya adanya tempat ketiga di setiap wilayah namun hal ini belum sepenuhnya diakui adanya, oleh karena itu peluang untuk berkumpul di tempat ketiga masih kurang. Dalam buku "The Great Good Place" (Ray Oldenberg, 1989), terdapat delapan ciri terbentuknya third place yakni, On Neutral Ground, Leveler, Conversation Is The Main Activity, Accessibility And Accommodation, The Regular, Low Profile, Mood is Playful, dan A Home Away From Home.

\section{Stres Pekerjaan}

Stres pekerjaan merupakan bagian dari permasalahan kehidupan yang merupakan kondisi di mana beban, tekanan, konflik, keletihan, kecemasan, panik dan hilangnya daya seorang karyawan. Penyebab stres Kerja bersumber dari tempat kerja di bagi dalam empat kategori yakni lingkungan fisik, meliputi cahaya, suara, suhu, ventilasi. Selanjutnya individu, meliputi 
konflik peran, peran ganda, beban kerja yang berlebihan, tidak ada kontrol, tanggung jawab, dan kondisi kerja. Kemudian kelompok, hubungan yang kurang baik dengan lawan, bawahan, dan atasan karena kurangnya berinteraksi atau sosialisasi antar sesama (Gibson, 2013:158).

\section{Relaksasi}

Teknik relaksasi adalah bentuk terapi berupa pemberian instruksi kepada seseorang untuk menutup mata dan berkonsentrasi pada pernafasan sehingga tercipta keadaan yang nyaman dan tenang, serta memberikan instruksi berupa gerakan-gerakan mulai dari kepala sampai kaki yang tersusun secara sistematis untuk melatih otot menjadi rileks. Mengendurnya otot-otot tubuh yang tegang menjadi rileks (santai) akan tercipta suasana perasaan yang tenang dan nyaman (Beck, 1995; Wirahmihardja, 2004; Kurniawan, 2009).

\section{Relaksasi terhadap Biophilic Design}

Pada sebuah jurnal berjudul "14 Patterns of Biophilic Design" (Terrapin Bright Green, 2012) disebutkan bahwa biophilic design dapat membantu mengurangi tingkat stres pada seseorang. Biophilic Design terdapat 14 pola yang dapat dikelompokkan menjadi tiga yaitu nature in the space pattern, natural analogues pattern, dan nature of the space pattern. Nature in the space pattern membahas kehadiran langsung tentang alam dalam suatu ruang. Ini termasuk kehidupan tanaman, air dan hewan, serta angin, suara, aroma dan elemen alam lainnya. Nature in the space pattern dapat dicapai melalui penciptaan sebuah makna, koneksi langsung dengan unsur-unsur alam, khususnya melalui keragaman, gerakan dan interaksi multi-indera. Natural analogues pattern membahas organik, non-hidup, dan sesuatu tidak langsung dari alam. Bentukan benda, bahan, warna, bentuk, urutan dan pola yang ditemukan di alam, bermanifestasi sebagai karya seni, ornamen, furnitur, dekorasi, dan tekstil di lingkungan dibangun. Natural analogues pattern dicapai dengan memberikan informasi dengan cara yang terorganisasi dan terkadang juga berkembang. Nature of the Space Pattern membahas konfigurasi spasial yang berada di alam, dapat melihat secara luas lingkungan sekitar, terlihat sedikit berbahaya atau tidak diketahui, view dikaburkan maupun terlihat pewujudannya, fobia yang merangsang sifat ketika mereka merupakan elemen terbesar dari keselamatan. Nature of the space pattern dicapai melalui penciptaan konfigurasi spasial yang disengaja dan menarik yang bercampur dengan nature in the space pattern dan natural analogues pattern.

\section{METODE}

\section{Metode Pengumpulan Data}

Metode ini di bagi dua yakni secara primer dan sekunder. Metode pengumpulan data secara primer antara lain berupa studi lapangan dan dokumentasi, merupakan bagian dari rangkaian penelitian dengan menganalisa berbagai dokumen baik data maupun gambar yang berkaitan dengan tujuan penelitian. Studi lapangan di lakukan pada tanggal 9 Februari 2020 dan tanggal 12 Februari 2020 di kawasan Blok M, Kelurahan Melawai, Kecamatan Kebayoran Baru, Jakarta Selatan, DKI Jakarta.
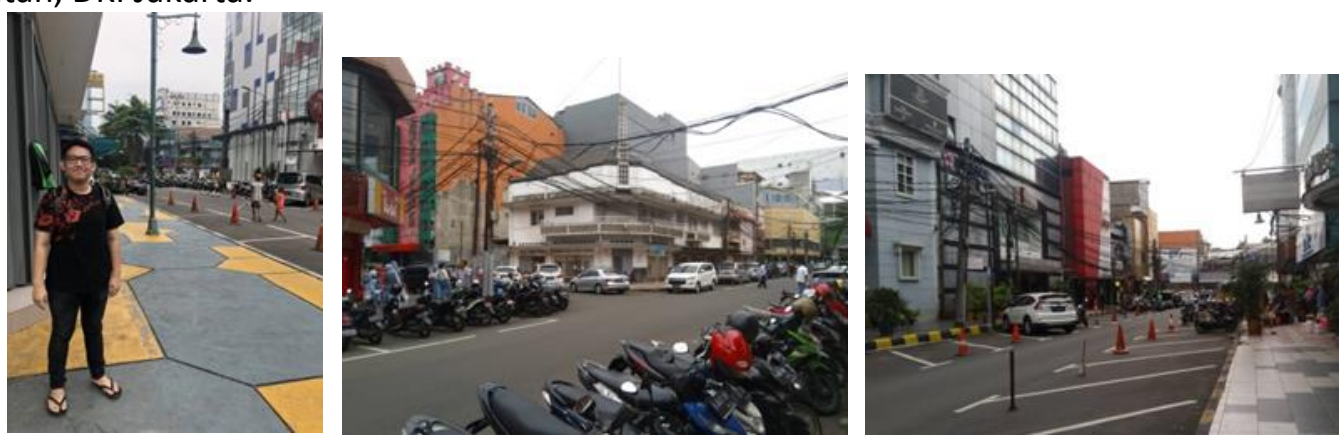

Gambar 1. Kawasan Blok M, jalan Melawai 6 Sumber: Penulis, 2020 
Selanjutnya adalah Metode pengumpulan data secara sekunder berupa studi literatur yang digunakan sebagai referensi berupa buku, jurnal, artikel, dan karya ilmiah lainnya. Dalam perancangan "Tempat Santai di Blok M" ini, studi literatur dimanfaatkan untuk pencarian data yang berkaitan proyek bangunan dengan Literatur mengenai "third place" dan "open architecture", karakteristik yang dimiliki dan isu-isu yang berkaitan serta literatur mengenai stres. Kemudian literatur kawasan dan tapak yang telah ditetapkan pemerintah yang menjadi acuan sebagai bahan pertimbangan analisis proses perancangan.

\section{Metode Komparatif}

Digunakan metode komparatif dalam pembuatan jurnal menggunakan perbandingan bagian dari studi preseden. Studi preseden yang digunakan sebagai referensi berdasarkan proyekproyek arsitektur yang berkaitan dengan isu third place dan isu stres dilihat dari karakteristik desain, program bangunan, dan komposisi ruang.

Tabel 1. Studi Preseden

\begin{tabular}{|c|c|c|c|}
\hline Studi Proyek & Karakteristik Desain & Program Bangunan & Komposisi Ruang \\
\hline Water Park Aqualagon & $\begin{array}{l}\text { Desain dari } \\
\text { bangunan ini } \\
\text { terinspirasi dari } \\
\text { origami dengan } \\
\text { berbagai lekukan } \\
\text { tajam yang } \\
\text { merupakan karakter } \\
\text { dari origami. } \\
\text { Bangunan ini dibuat } \\
\text { bagaikan sebuah } \\
\text { landscape yang } \\
\text { menjulang tinggi ke } \\
\text { atas. }\end{array}$ & $\begin{array}{l}\text { sebuah taman } \\
\text { rekreasi air }\end{array}$ & $\begin{array}{l}\text { Bangunan ini merupakan } \\
\text { bagaikan sebuah } \\
\text { landscape yang } \\
\text { menjulang tinggi ke atas. } \\
\text { Landscape ini terbuka } \\
\text { untuk publik dan } \\
\text { merupakan salah satu } \\
\text { fungsi utamanya. Dan } \\
\text { pada akhirnya, bangunan } \\
\text { ini menjadi landmark dari } \\
\text { daerah tersebut yang } \\
\text { menyediakan } \\
\text { pemandangan yang indah } \\
\text { akan desa tersebut. }\end{array}$ \\
\hline The Pit House & $\begin{array}{l}\text { Bangunan ini dibuat } \\
\text { dengan mem- } \\
\text { pertimbangkan unsur } \\
\text { sosial yang terbuka, } \\
\text { interaktif, fungsional, } \\
\text { dan dinamis. Selain } \\
\text { itu }\end{array}$ & $\begin{array}{l}\text { sebuah tempat } \\
\text { komunitas otomotif } \\
\text { berkumpul } \\
\text { sekaligus } \\
\text { memanjakan } \\
\text { kendaraan yang } \\
\text { mereka bawa } \\
\text { masing - masing. Di } \\
\text { area ini pengunjung } \\
\text { dapat melakukan } \\
\text { perawatan } \\
\text { kendaraan, } \\
\text { berkumpul dengan } \\
\text { sesama pemilik } \\
\text { kendaraan, atau } \\
\text { hanya sekedar } \\
\text { untuk parkir. }\end{array}$ & $\begin{array}{l}\text { bangunan ini memainkan } \\
\text { layer sehingga fungsi } \\
\text { dapat diperluas sesuai } \\
\text { kebutuhan bangunan } \\
\text { dan bangunan terlihat } \\
\text { menarik karena } \\
\text { permainan peil lantai. }\end{array}$ \\
\hline
\end{tabular}




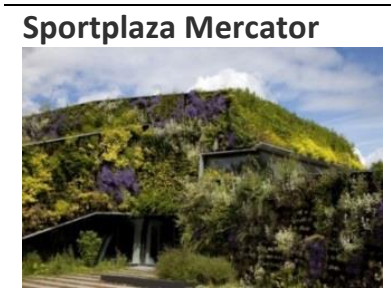

Sumber: Penulis, 2020
Desain bangunan ini Terdapat beberapa

berdasarkan dari fungsi kesehatan

kebutuhan

lingkungan

setempat yang

membutuhkan

sebuah "boost"

dalam menyatukan

perbedaan dan

keragaman yang ada

di daerah sekitarnya

dan juga bangunan

ini didesain di

sebuah taman,

maka dari itu, fasad

dari bangunan ini

juga mengutamakan

tanaman.

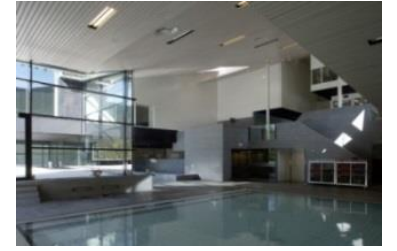

Salah satu desain yang diunggulkan di proyek ini merupakan bagaimana orang - orang dapat melihat aktivitas yang sedang dikerjakan orang lain. Seperti contohnya kolam renang ini dapat terlihat dari café yang berada di lantai atas. Sehingga , orang - orang dapat melihat dan juga terlihat dan terjadi sebuah perspektif baru terhadap para pengunjung yang beragam.

\section{DISKUSI DAN HASIL}

Proyek ini terletak Tapak berada di, Kelurahan Melawai, Kecamatan Kebayoran Baru, Jakarta Selatan, DKI Jakarta, 12130. Luas Kelurahan Melawai yakni 1,23 Km². Kawasan Blok M, memiliki aktivitas yang tidak pernah berhenti. Selain itu kawasan tersebut memiliki kawasan Transit Oriented Development yakni stasiun MRT blok BCA dan Terminal Blok M, membuat padatnya aktivitas yang terjadi di kawasan tersebut. Dari diskusi yang di dapatkan hasil yang di dapatkan di bagi dua yakni secara non fisik dan fisik.

\section{Deskripsi Non Fisik (Konsep Program)}
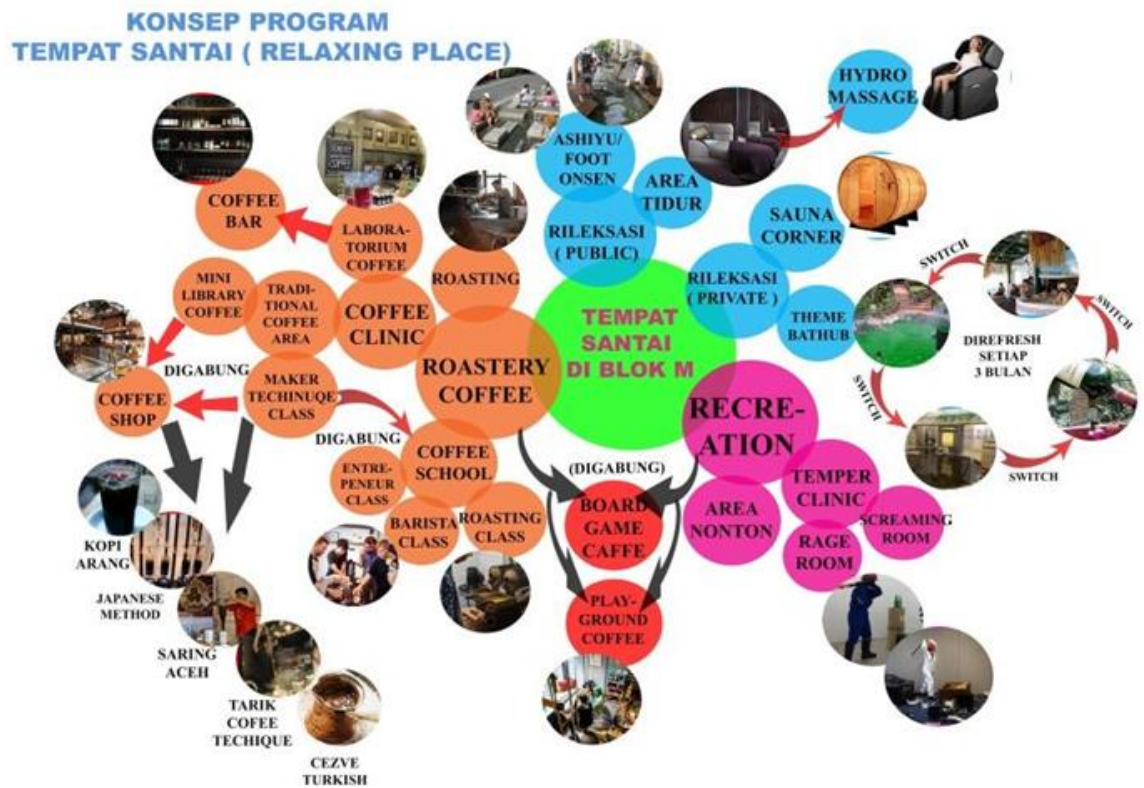

Gambar 2. Konsep Program

Sumber: Penulis, 2020 
Program dalam proyek ini menyediakan tempat bagi masyarakat dimana terdapat area relaksasi, rekreasi, serta sosialisasi. Rileksasi yang di berikan di bagi dua yakni publik dan privasi. Area publik dibuatkan program yakni footbathub serta area privasi diberikan program theme onsen. Area rekreasi dibuatkan program temper clinic sebagai sarana hiburan luapan dari stres pengunjung. Kemudian untuk sosialisasi berupa area berkumpul bertema coffee shop, dikarenakan Kawasan Blok M banyak sekali kawula muda yang berkumpul di area coffee shop akan tetapi kapasitas setiap coffee shop tidak banyak sehinggan timbul ide dalam perancangan untuk memasukkan program coffee shop yang dibagi beberapa area didalamnya.

\section{Deskripsi Non Fisik (Konsep Gubahan)}

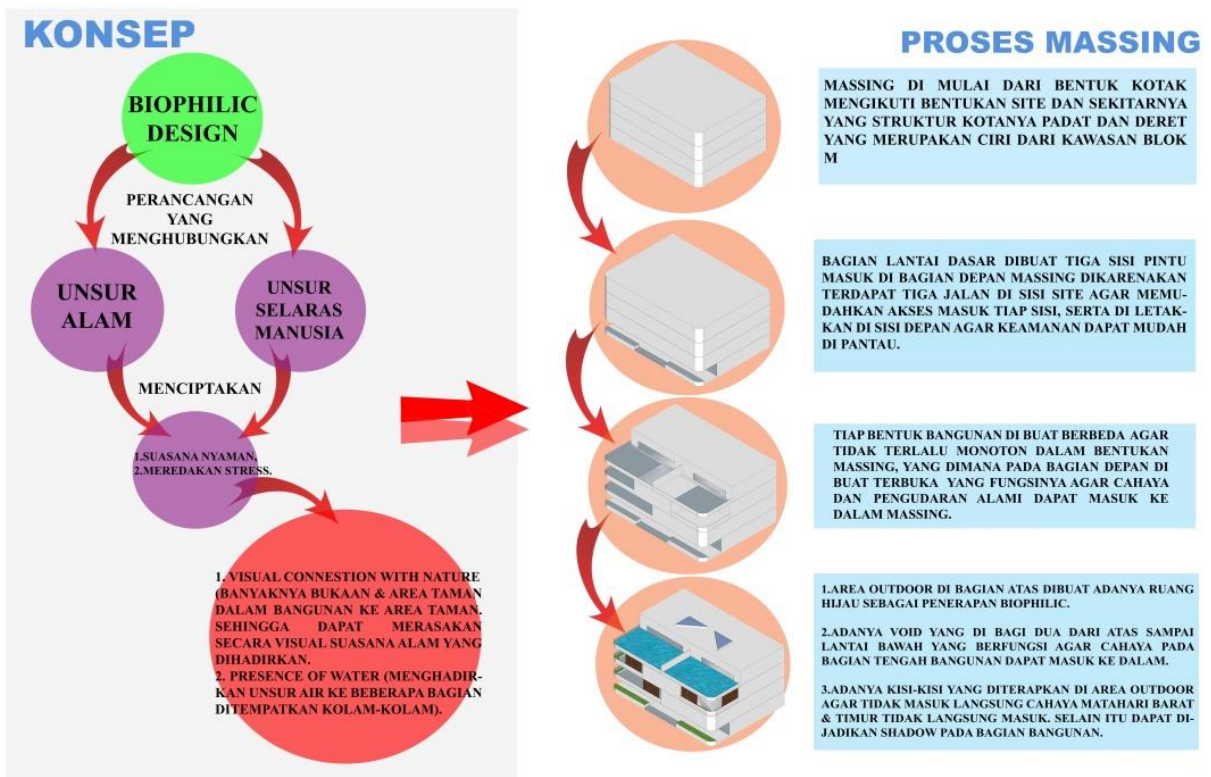

Gambar 3. Konsep Bangunan

Sumber: Penulis, 2020

Konsep bangunan menerapkan biophilic design yang menghubungkan antara alam dan keselarasan manusia, dimana point-point pada biophilic design adalah mengutamakan keterbukaan, kehijauan, serta adanya air berupa kolam yang memiliki kesesuaian untuk menunjang program relaksasi dan interkasi sosial pada bangunan sehingga dapat tercapainya ruang untuk bersantai bagi pengunjung yang datang.
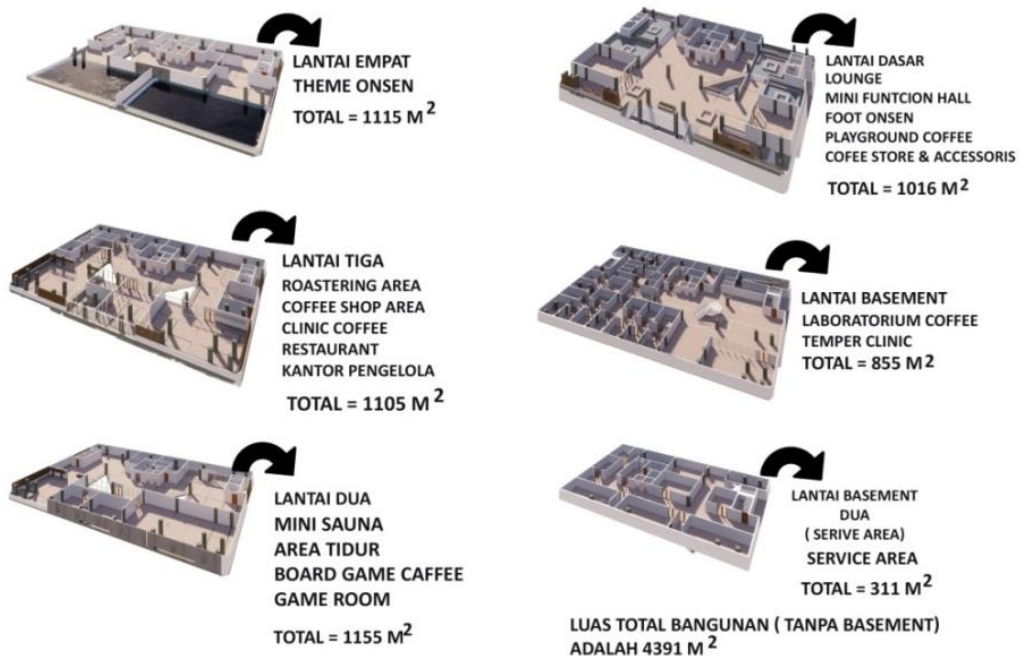

Gambar 4. Exploded Aksonometri Sumber: Penulis, 2020 
Gambar diatas merupakan program ruang beserta denah aksonometri pada proyek bangunan di kawasan Blok $\mathrm{M}$ dengan luasan total bangunan adalah $4.391 \mathrm{~m}^{2}$. Pada lantai dasar secara keseluruhan bersifat publik kemudian naik setiap lantainya dengan programnya bersifat secara privasi serta kemungkinan kapasitas pengunjung yang akan datang.

\section{Deskripsi Fisik (Analisa Messo)}
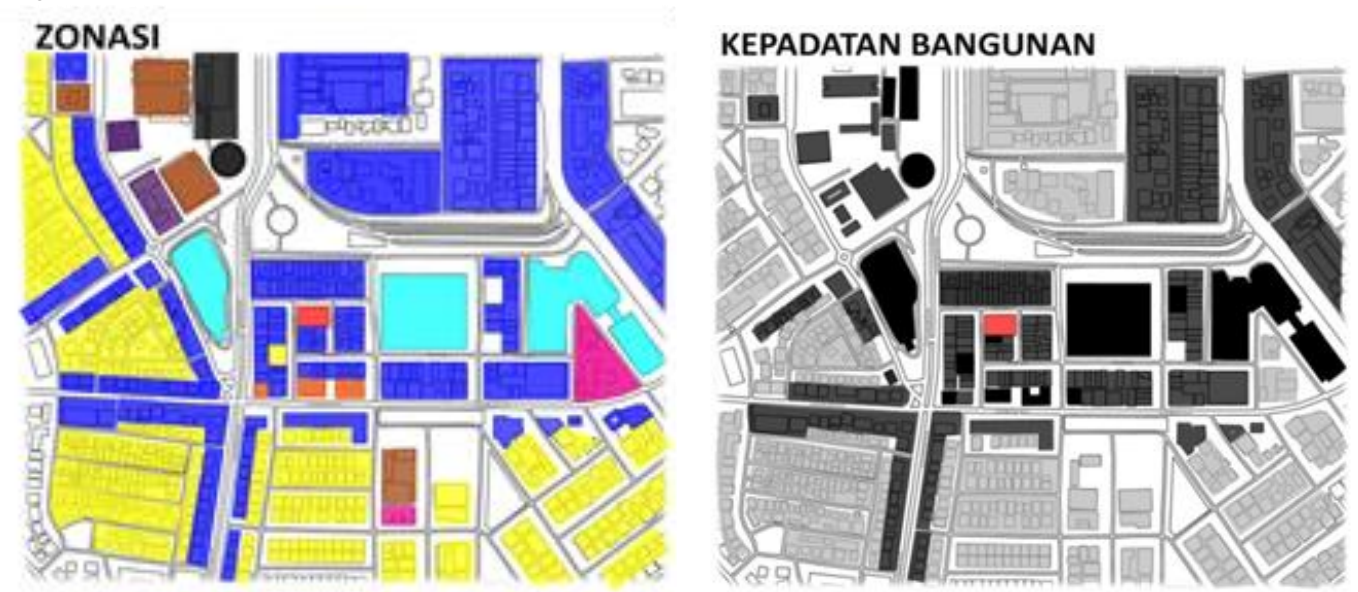

Gambar 5. Analisis Zonasi Messo (kiri), Analisis Kepadatan Bangunan Messo (kanan) Sumber: Penulis, 2020

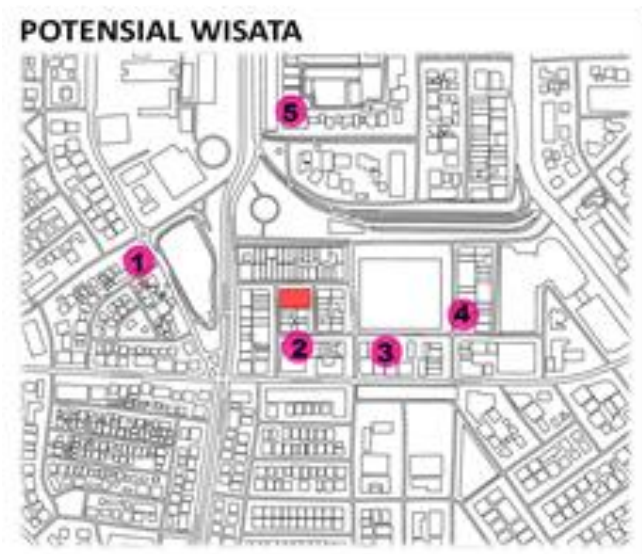

Gambar 6. Analisis Potensial Wisata (Messo) Sumber: Penulis, 2020

Kawasan Blok M, Kelurahan Melawai, Kecamatan Kebayoran Baru, Jakarta Selatan memiliki kepadatan aktivitas yang intens di hari senin sampai minggu dengan dominan pekerjannya adalah Pedagang, Karyawan, dan di dominasi oleh kawula muda. Kawasan Blok M memenuhi karakteristik dari objek perancangan yaitu komersil dan hiburan. Zonasi di kawasan Blok M lebih banyak perdagangan baik secara high rise maupun middle rise, sehingga aktivitas manusianya pun sangat padat. Tapak merupakan rembesan karena berada di antara sekitaran second place dan di ruas selanjutnya area first place, Maka dibutuhkan ruang untuk istirahat atau relaksasi sementara pada saat jam istirahat atau pulang kerja. Dominan padatnya bangunan di kawasan Blok $\mathrm{M}$ adalah middle rise berupa pertokoan dan high rise berupa pusat perbelanjaan serta gedung perkantoran. Bangunan berupa pertokoan dan pusat perbelanjaan yang secara masif sifatnya lebih tertutup, sehingga menimbulkan stres, dibutuhkan sebuah bangunan dengan bentukan yang lebih terbuka dan dinamis. 


\section{Deskripsi Proyek}

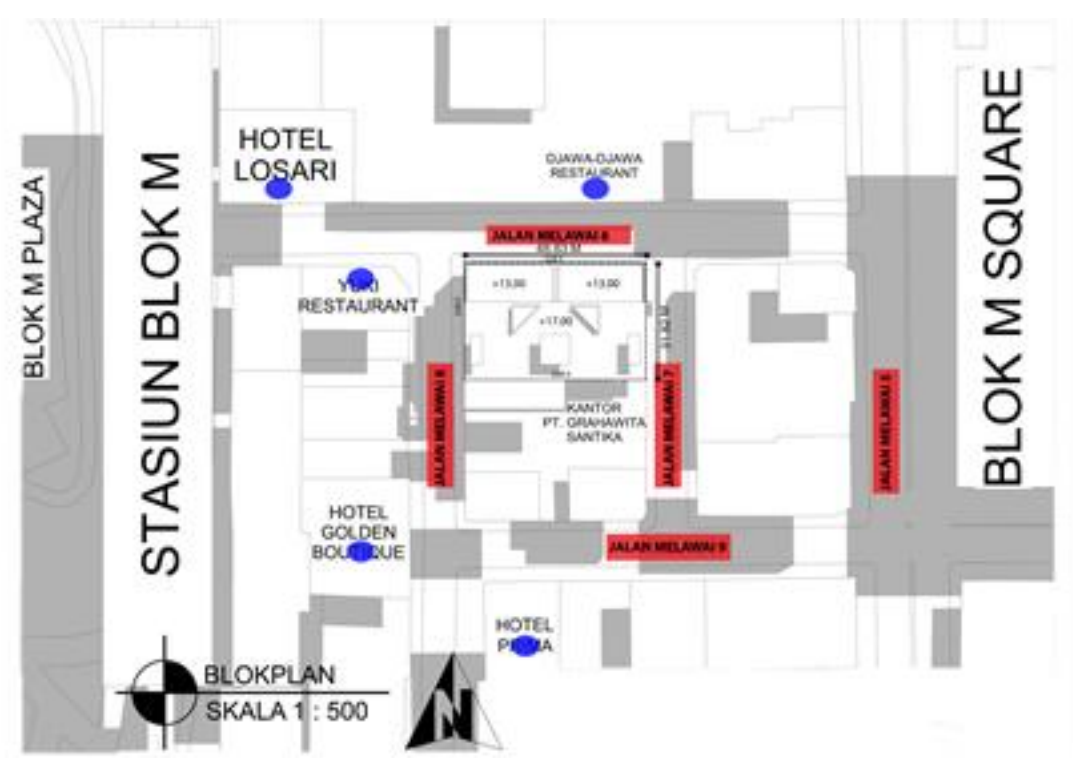

Gambar 7. Blockplan

Sumber: Penulis, 2020

Site ini memiliki luas tapak sebesar $1.570 \mathrm{~m}^{2}$, dengan luas total bangunan sebesar $4.391 \mathrm{~m}^{2}$. Tinggi bangunan maksimal lahan ini adalah empat lantai dengan peruntukan perdagangan dan jasa, untuk daerah hijau sebesar $550 \mathrm{~m}^{2}$ (35\%), luas dasar bangunan maksimal sebesar 1.020 $\mathrm{m}^{2}(65 \%)$, dengan GSB sebesar 0 dikarenakan tipe bangunan adalah deret. Pada sisi sebelah utara, barat, dan timur bangunan dibuat entrance untuk pejalan kaki di karenakan adanya tiga sisi jalan sekitar tapak. Bangunan pun berada tepat di sisi kawasan rembesan antara first place dan second place yang area tersebut banyak tempat hiburan berupa bar, restaurant, dan hotel yang tidak semua orang dapat masuk. Terdapat area transit oriented development berupa stasiun MRT blok BCA, dan Terminal Blok M sehingga area tersebut membutuhkan third place.
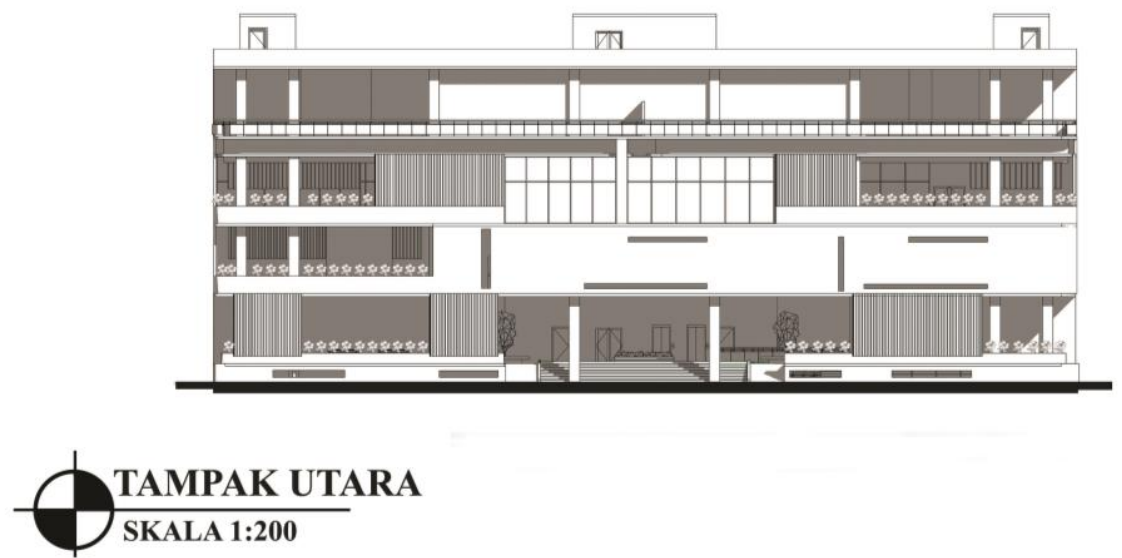

Gambar 8. Tampak Bangunan Utara Sumber: Penulis, 2020 

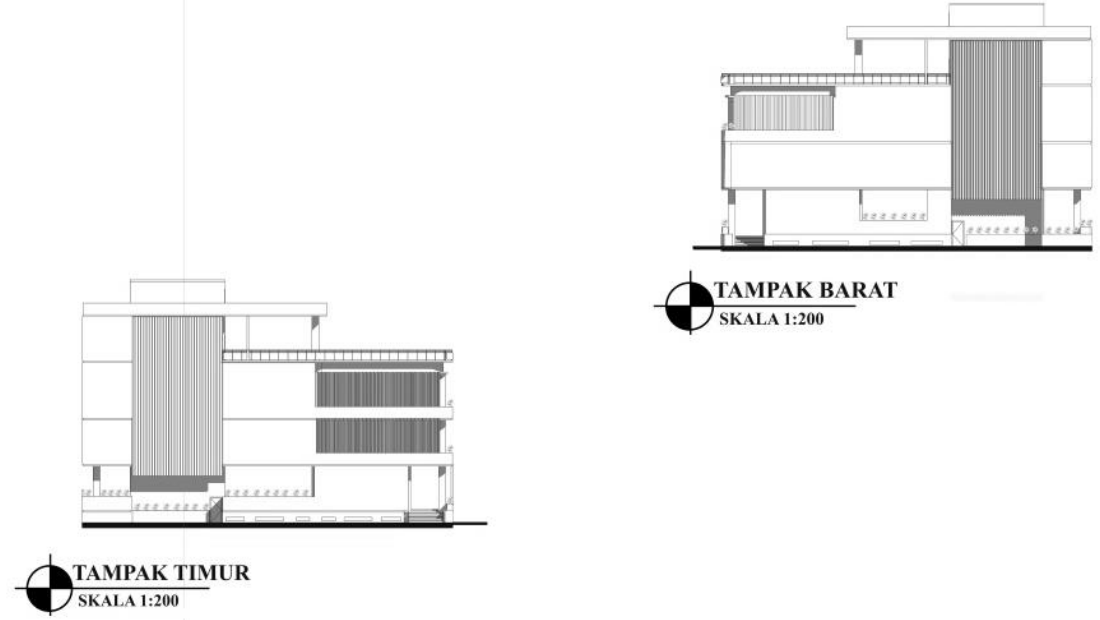

Gambar 9.Tampak Bangunan Barat dan Timur Sumber: Penulis, 2020

Fasad yang di berikan pada bangunan mengikuti kawasan Blok M. Untuk mempercantik bangunan diberikan kisi-kisi aluminium bermotif kayu, berfungsi juga sebagai pencegahan cahaya matahari timur dan barat tidak langsung masuk ke dalam bangunan serta memberikan efek bayangan pada dalam bangunan. Kemudian penulis memperlihatkan bagian eksterior dan interior bangunan. Berikut ini menggambarkan beberapa suasana luar dan dalam proyek beserta lingkungan sekitar. Suasana tersebut antara lain eksterior beserta lingkungan sekitar, kemudian terdapat suasana dalam antara lain theme onsen pool, footbathub, lobby dan mini function hall serta restaurant.
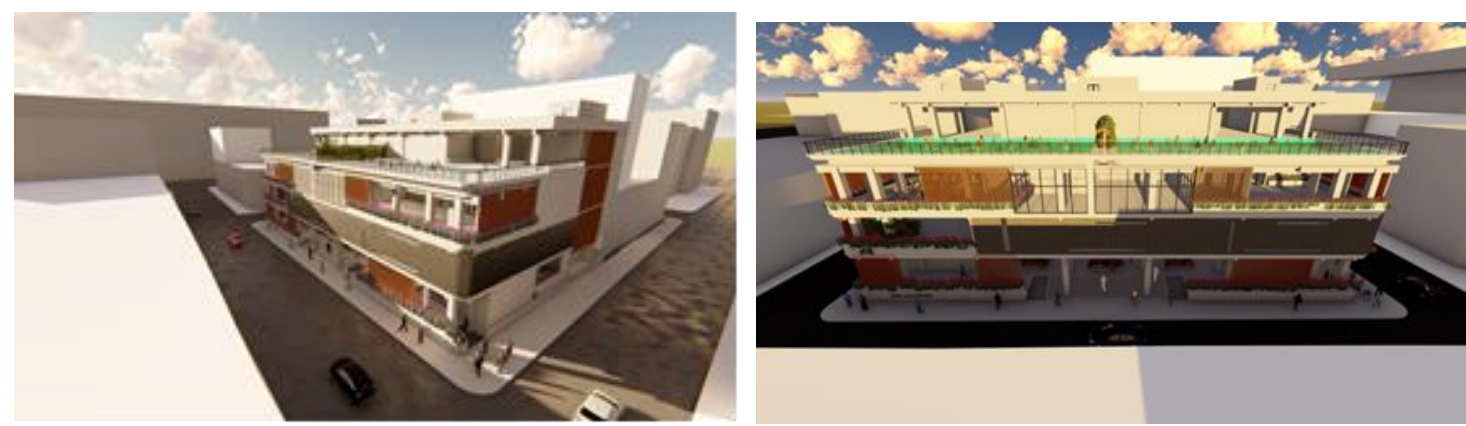

Gambar 10. Eksterior Bangunan

Sumber: Penulis, 2020
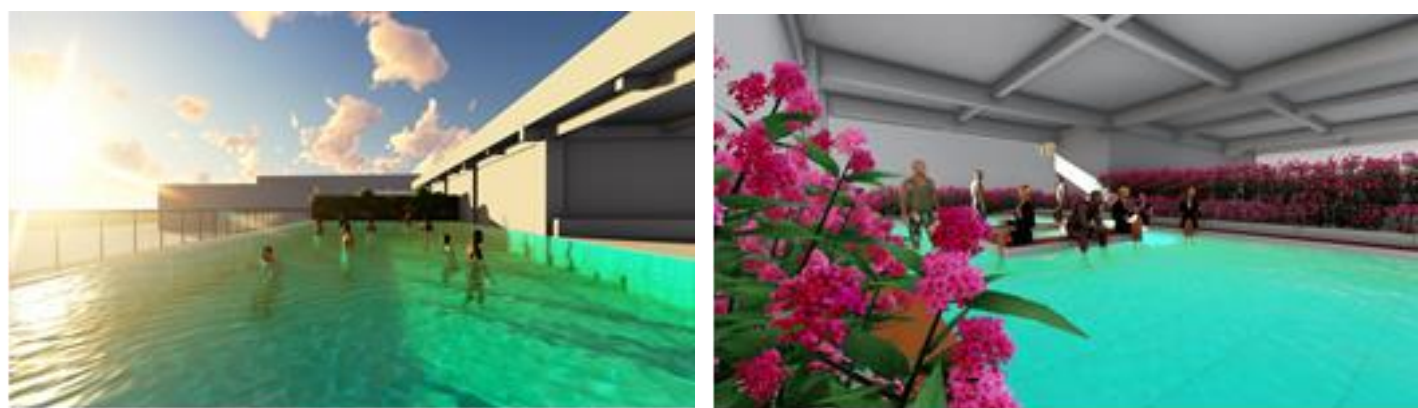

Gambar 11. Interior Theme Onsen Pool (kiri), footbathup (kanan) Sumber: Penulis, 2020 

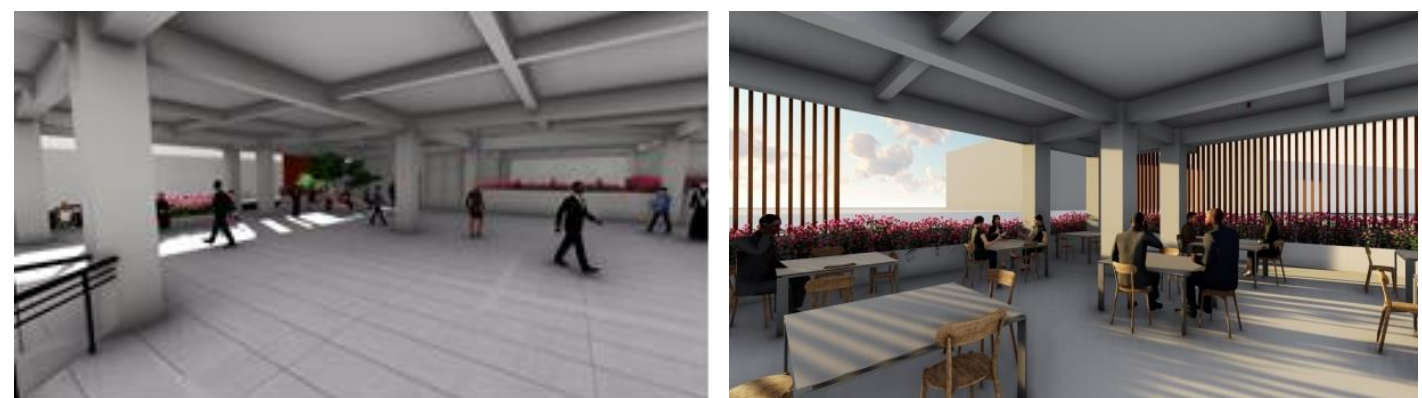

Gambar 12. Interior Lobby \& Mini Function hall (kiri), Interior Restaurant (kanan)

Sumber: Penulis, 2020

\section{KESIMPULAN DAN SARAN}

\section{Kesimpulan}

Berdasarkan hasil yang di peroleh dibutuhkan ruang publik yang dapat mewadahi para pedagang, karyawan, maupun masyarakat yang datang di kawasan Blok $\mathrm{M}$ untuk mengisi waktu kosong mereka. Untuk menjawab kebutuhan tersebut maka di usulkan sebuah third place yang mengedepankan tentang relaksasi, rekreasi dan interkasi sosial di kawasan Blok $\mathrm{M}$ dalam menanggapi kondisi dan isu tersebut. Adanya ruang terbuka dan hijau pada bangunan agar terciptanya nuansa alam yang merupakan bagian penerapan dari biophilic design dan dapat dijangkau oleh semua kalanga. Pada bangunan diusulkan kegiatan untuk mengurangi tingkat stres sebagai akibat dari aktivitas yang dilakukan setiap hari. Program utama dalam proyek ini yaitu berupa foot bathtub, theme onsen, temper clinic, area tidur, area nonton, dan coffee shop yang terbagi beberapa ruang yang bertujuan untuk mewadahi interaksi sosial masyarakat tanpa adanya batasan tertentu di kawasan Blok M.

\section{Saran}

Kelebihan pada penelitian ini adalah ditemukannya secara langsung kondisi permasalahan tingkat stres di kawasan Blok $\mathrm{M}$ namun memiliki kekurangan pada literatur-literatur mengenai permasalahan stres di kawasan Blok M. Penelitian ini masih perlu adanya dukungan yang positif untuk mengembangkan desain dan ide yang dapat menjadi solusi untuk isu stres yang terjadi dalam masyarakat.

\section{UCAPAN TERIMA KASIH}

Penulis mengucapkan terima kasih kepada Dosen Pembimbing, Ketua Jurusan Arsitektur dan Perencanaan, Kaprodi S1 Arsitektur, serta pihak-pihak lainnya yang telah memberikan pengarahan, petunjuk, dan bimbingan yang memungkinkan terselesaikannya jurnal ini.

\section{REFERENSI}

Mangunwijaya, YB. (1992). Wastu Citra. Jakarta: PT. Gramedia.

Oldenburg, R. (1989). The Great Good Place. USA: Da Capo Press.

Romadhani, I., Suryawan. A. (2017). Desain Ruang Relaksasi untuk Stres di Perkotaan dengan Penerapan Biophilic Design. 6 (2). 2337-3520.

Suyono., Triyono., Handarini, D. (2016). Keefektifan Teknik Relaksasi untuk Menurunkan Stres Akademik Siswa SMA. 4 (2), 115-120.

Tibbalds, F. (1992). Making People-Friendly Towns: Improving The Public Environment In Towns And Cities. Longman, Harlow, Essex.

Firdhy, E. C. (2020). Jakarta: Kota dengan Tingkat Stress Ke Enam Dunia. https://data.tempo.co/read/594/jakarta-kota-dengan-tingkat-stress-ke-enam-dunia (di akses tanggal 12 February 2020). 
